$64 \mid$ InterAção

\title{
A REPERCUSSÃO DO MERCOSUL LEGISLATIVO: DEFICIÊNCIAS DE UMA OPÇÃO PELA INTERGOVERNABILIDADE
}

\author{
Augusto Jaeger Junior ${ }^{1}$
}

Mariana Sebalhos Jorge ${ }^{2}$

\section{Resumo}

O presente estudo realiza uma análise da evolução do processo integracionista do Mercosul. Ressalta a fragilidade institucional do Mercosul e as principais tentativas de harmonização legislativa. É destacada a controversa adesão da Venezuela como membro permanente e a sua recente suspensão por não cumprir a cláusula democrática. Ao final, apresenta uma perspectiva positiva do processo de integração do Mercosul.

Palavras-chave: Mercosul; harmonização; fragilidade institucional; defesa do processo integracionista.

\begin{abstract}
The study analyzes the evolution of the Mercosur integration process. It underscores the institutional fragility of Mercosur and the main attempts at legislative harmonization. Of note is the controversial membership of Venezuela as a permanent member and its recent suspension for failing to comply with the democratic clause. At the end, there is a positive perspective on the Mercosur integration process.
\end{abstract}

Keywords: Mercosur; harmonization; institutional fragility; defense of the integrationist process.

\footnotetext{
${ }^{1}$ Doutor em Direito Comunitário pela Universidade Federal do Rio Grande do Sul, sob a orientação da Profa. Dra. Cláudia Lima Marques. Professor Associado da Faculdade de Direito da UFRGS, em Porto Alegre, Brasil, onde leciona as disciplinas de Direito Internacional Privado e Direito Internacional da Concorrência em níveis de graduação e pós-graduação. Autor dos livros "Liberdade de Concorrência na União Européia e no Mercosul" e "Direito Internacional da Concorrência", lançados pelas Editoras LTr e Juruá, entre outros. Líder do Grupo de Pesquisa “Direito Internacional da Concorrência” (UFRGS/CNPq). E-mail: augusto.jaeger@ufrgs.br

2 Mestra junto ao Programa de Pós-Graduação em Direito da Universidade Federal do Rio Grande do Sul (UFRGS). Bacharel em Relações Internacionais pela Universidade Federal de Santa Maria (UFSM). Bacharel em Direito pelo Centro Universitário Franciscano (UNIFRA). Pesquisadora do Grupo de Pesquisa "Direito Internacional da Concorrência" (UFRGS/CNPq). E-mail: msebalhos@gmail.com
} 
65 InterAção

\section{INTRODUÇÃO}

Nesse artigo, são apontados os impasses enfrentados pelo processo de integração do Mercosul como um todo, a fragilidade do sistema de solução de controvérsias e da aplicação de suas normas, bem como os recentes desenvolvimentos do Mercosul com a adesão da Venezuela e a sua recente suspensão. Ao final, apresenta-se, com base em doutrina estrangeira, uma defesa do processo de integração e algumas alternativas para o desenvolvimento do Mercosul.

A cooperação econômica entre Brasil e Argentina da década de 80 foi vista como precursora desse processo (SALOMÃO FILHO; SAMTLEBEN, t. I, 1991, p. 1346). O seu objetivo principal era a conformação de um mercado comum, fase que enseja a presença das liberdades fundamentais (SALOMÃO FILHO; SAMTLEBEN, t. II, p. 1389). O Mercosul trata-se de uma nova espécie de projeto de integração e o direito dele emergente, que por si só é um modelo novo de direito ${ }^{3}$, visto como formador de novo ramo (WEHNER, 1999, p. 2).

Com efeito, a assinatura do tratado permitiu a vinculação contratual à luz do direito internacional público ${ }^{4}$ entre países para a fundação de um mercado comum e é a pedra fundamental para o processo de integração. Mas,

\footnotetext{
${ }^{3}$ Sobre ser 0 direito dele emergente um modelo novo de direito, que prevê até uma Decisão de $n$. 23/2000 CMC sobre a incorporação da normativa Mercosul ao ordenamento jurídico dos Estados-partes, que cria um sistema de monitoramento de incorporações, ver MARQUES, 2001, p. 73-100. Ver a Decisão referida em ETCHEVERRY; ETCHEVERRY, 2001, p. 306-308. A normativa Mercosul em junho de 2000 correspondia a aproximadamente 200 decisões, 800 resoluções e 100 diretrizes (SAMTLEBEN, 2001, p. 56). Ainda vale fazer menção à Decisão n. 20/02 CMC, que busca prevenir 0 atraso da incorporação, a transposição incorreta e a incompatibilidade das normas do Mercosul com os ordenamentos internos. Segundo dados oficiais, apenas 50 por cento das normas estão em vigor. Algumas áreas são especialmente problemáticas, como justiça, com 20 por cento, e saúde, com 54 por cento. A afirmação de que as dificuldades de incorporação resultam da omissão ou da negligência dos Estados-partes não corresponde com a realidade. Elas resultam muito mais de um conjunto de condicionantes. Para 0 atual estágio de implantação das normas ver o PRIMER Informe Semestral de la Secretaría del Mercosur: un foco para el proceso de integración regional, p. 9 e 32-54 e o SEGUNDO informe sobre la aplicación del derecho del MERCOSUR por los tribunales nacionales (2004), $587 \mathrm{p}$.
}

${ }^{4} 0$ bloco como fenômeno do direito internacional público clássico é apresentado em VENTURA (2003, p. 127). 
66 InterAção

como ele mesmo expressa, é um tratado para a constituição do mercado comum, isto é, um evento futuro, que não começaria com a entrada em vigor dele próprio. O Tratado é apenas o ponto de partida (WEHNER, 1999, p. 73-74).

\section{0 INÍCIO DO PROCESSO DE INTEGRAÇÃO: DO PERÍODO DE SUCESSO À CRISE}

O Protocolo de Ouro Preto, de 1994 (SAMTLEBEN, 1996, p. 1997), implementou uma união aduaneira, disciplinando as regras sobre a tarifa externa comum (SAMTLEBEN, 1995, p. 129). Este documento do direito primário sublinhou uma vez mais a opção por um caráter intergovernamental ${ }^{5}$ do processo, em que as decisões são tomadas por consenso e com a presença de todos os Estados-partes (SALOMÃO FILHO; SAMTLEBEN, t. II, 1992, p. 1385 e 1388), caráter que representa a maior assimetria entre este processo e o da União Europeia (VENTURA, 2003, p. 694). O mero estabelecimento de uma tarifa não determina, no entanto, a remoção do sistema de controle de origem, sendo necessário a unificação das regras de aduana, da política de comércio exterior e a harmonização da legislação nacional.

Em 1996, o processo recebeu dois novos parceiros, na condição de Estados associados (RAMOS, 2000, p. 24-25), sendo eles o Chile e a Bolívia, através de acordos de associação (DROMI SAN MARTINO, 2002, p. 299-304; VENTURA, 2003, p. 575-581 e JAEGER JUNIOR, 2006, p. 53). O crescimento econômico e as associações ocorridas fortaleceram a posição do Mercosul perante outros significativos parceiros (SAMTLEBEN, 1998, p. 65). Na mesma

\footnotetext{
${ }^{5}$ Há vozes que consideraram a preferência por instituições não burocratizadas como uma demonstração de que 0 Mercosul sempre foi concebido mais como uma estratégia comunitária de exportação do que perseguidor de um mercado interno, ou mesmo uma opção para não conflitar com a até então atingida dinâmica do processo. GRATIUS, 1988, p. 305 e 309.
} 
67 InterAção

época, o bloco estabeleceu uma forte relação de cooperação com a União Europeia, bem como com numerosas outras organizações e países ${ }^{6}$. As relações com a União Europeia remontam quase ao tempo da sua fundação, pelo que ela foi considerada a madrinha do Mercosul (VENTURA, 2003, p. 413), quando foi celebrado o Acordo de Cooperação Institucional entre a Comissão Europeia e o Conselho do Mercosul (VENTURA, 2003, p. 322 e p. 415). Posteriormente, em 1995 foi celebrado o Acordo-quadro Inter-regional de Cooperação entre a União Europeia e o Mercado Comum do Sul, que tinha como principais tarefas a liberalização gradual e progressiva do comércio, e a ampliação da cooperação econômica.

O Mercosul gerou mais ganhos que qualquer organização anterior da qual fossem integrantes os seus Estados-partes e dispôs de uma condizente estrutura institucional (SALOMÃO FILHO; SAMTLEBEN, t. II, p. 1390) e tornou-se um mercado interessante para os investidores estrangeiros (SALOMÃO FILHO; SAMTLEBEN, t. II, p. 2005), sendo o terceiro mais importante bloco econômico no mundo ${ }^{7}$. Apesar do sucesso, o bloco passou a enfrentar nítidos problemas, alguns vinculados à abertura econômica, redução do aparato do Estado e à evolução de problemas sociais como desemprego e miséria (GRATIUS, 1988, p. 307). Ainda que não seja tão visível um retrocesso

\footnotetext{
${ }^{6}$ As relações internacionais do Mercosul com os Estados Unidos da América, em função do acordo entre os quatro países do Mercosul e estes, chamado de Rose Garden Agreement ou Acordo 4+1, de 1991, com o Canadá, com 0 Bloco Asiático, entre outros, podem ser conferidas em RAMOS (2000, p. 25-28), DROMI SAN MARTINO (2002, p. 304-307). Acordos concluídos com os países da América Latina estão citados em uma tabela em VENTURA (2003, p. 690-692). Uma cronologia das relações entre a União Europeia e a América Latina e o Caribe desde 1974 pode ser conferida em HACIA la III Cumbre Unión Europea - América Latina y el Caribe: Balances y perspectivas, $2004, \mathrm{p}$. 33-36. A lenta construção das relações Europa-América Latina, antes mesmo da existência do Mercosul, é estudada por VENTURA (2003, p. 331-412), assim como a cronologia das relações entre a União Europeia e o Mercosul (2003, p. 659-661).

${ }^{7}$ Ou o segundo, atrás do Nafta, como quer GRATIUS (1988, p. 304). Ou ainda o quarto, como quer WEHNER (1999, p. 23).
} 
68 | InterAção

no processo do Mercosul, seguiu-se ao período de sucesso uma forte merco esclerosis 8 .

Desde 1999 os Estados-partes vêm enfrentando severas crises econômicas que tiveram fortes reflexos no Mercosul $^{9}$ (BARRAL, 2003, p. 85). Primeiro foi o Brasil que precisou desvalorizar a sua moeda em janeiro em trinta por cento frente ao dólar. A Argentina instituiu cláusulas de salvaguarda frente ao Brasil, especialmente para os setores de calçados, frangos, têxteis e regime automotivo. Tal medida quase desencadeou o rompimento do Acordo Mercosul. Já em dezembro de 2001 a situação da economia argentina se agravou drasticamente ${ }^{10}$, de modo que as reações do governo argentino foram extremas. As tentativas de reaproximação entre os países eram intercaladas com períodos de crises.

\section{A SOLUÇÃO DE CONTROVÉRSIAS E A FRAGILIDADE INSTITUCIONAL}

Em função de obstáculos constitucionais e da opção pela intergovernabilidade, o mecanismo de solução de controvérsias assumiu uma característica diferente do existente na União Europeia. A possibilidade de recurso ao Tribunal Permanente de Revisão do Mercosul segundo o artigo 17 é o principal avanço do Protocolo de Olivos, de 2002, em relação ao sistema estabelecido anteriormente (PISCITELLO; SCHMIDT, 2006, p. 301-304). Até

\footnotetext{
8 Em adaptação do termo euro esclerosis, relacionado às crises enfrentadas pela Comunidade Europeia, utilizado por BIANCHI (1997, p. 25).

${ }^{9}$ A afetação da crise na competitividade dos Estados-partes, por exemplo, foi evidenciada por MARTINS (2001, p. 50-70).

10 Um diagnóstico dos acontecimentos deste ano pode ser visto na obra de ALMEIDA (2003, p. 111-122).
} 
69 | InterAção

então o sistema de solução de controvérsias não dispunha de instância recursal (SCHMIDT, 2005, p. 139-142).

A fragilidade institucional e jurídica ${ }^{11}$ do Mercosul é quase incontestável ${ }^{12}$. Mesmo não tendo uma base jurídica sólida, o Mercosul já atua e mesmo legisla um modelo novo de direito ${ }^{13}$. A aplicação das normas do Mercosul depende da Constituição de cada Estado-parte ${ }^{14}$, já que uma norma do Mercosul só tem efeito depois que todas as partes tiverem adotado as medidas necessárias segundo as leis nacionais, e existe uma ampla tendência nos países de dar preferência à Constituição nos casos de conflitos entre normas de direito internacional público e direito interno (SILVA, 2002, p. 48-49).

\section{A HARMONIZAÇÃO DAS REGRAS MATERIAIS}

No Mercosul, a efetivação das políticas de integração ocorre por meio de harmonização das legislações nacionais envolvidas - processo que não tem se mostrado fácil.

O Mercosul adotou duas medidas de harmonização relativas a investimentos estrangeiros, quais sejam o Protocolo de Colônia ${ }^{15}$ para a

\footnotetext{
11 Visões da fragilidade institucional podem ser vistas em MARQUES (2001, p. 83-87) e em VENTURA (2003, p. 108 e 589-601).

12 Ver uma contestação doutrinária estrangeira a essa constatação em JAEGER JUNIOR, 2006, p. 589.

13 Ver mais em DREYZIN DE KLOR, Adriana. EI Mercosur: Generador de una nueva fuente de derecho internacional privado. Buenos Aires: Zavalía, 1997. 395 p.

${ }^{14}$ A questão da hierarquia das normas emanadas dos órgãos do Mercosul na órbita interna é estudada por VENTURA (2003, p. 167-223), para quem os Estados-partes se dividem em potencialmente federalistas, sendo a Argentina 0 mais deles, e irredutíveis soberanistas, sendo o Uruguai o mais deles.

${ }^{15}$ Através do Protocolo de Colônia, os Estados-partes se obrigam a tratar os investidores dos outros parceiros de igual forma que tratam os seus nacionais. Esse Protocolo segue em estrutura e conteúdo o modelo dos mais modernos acordos de proteção a investidores (SAMTLEBEN, 1996, p. 1998).
} 
promoção e recíproca proteção de investimentos no Mercosul (Decisão n. 11/93) e o Protocolo de Buenos Aires ${ }^{16}$ relativo à promoção e proteção de investimentos provenientes de países não-participantes do Mercosul (Decisão n. 11/94). No âmbito da política de proteção da propriedade industrial, em agosto de 1995 os quatro países firmaram um Protocolo de harmonização de normas sobre propriedade intelectual em matéria de marcas, certificados de procedência e denominações de origem (Decisão n. 8/95) ${ }^{17}$. Há doutrinas também sobre uma harmonização no direito dos contratos internacionais (ARAUJO, 2004, p. 12-14 e 204). Outros âmbitos com chances de sucesso em termos de harmonização seriam o fiscal (XAVIER BASALDÚA, 1999, p. 208217), o direito do trabalho, a liberdade de estabelecimento e de prestação de serviços (MARQUES, 1998, p. 38-46) e o direito de sociedades ${ }^{18}$.

É preciso ressaltar a tentativa frustrada de harmonização em direito do consumidor e que evidenciou a fragilidade institucional ${ }^{19}$ do Mercosul (MARQUES, 2004, p. 405). Em 1994, o Mercosul começou a legislar sobre a

${ }^{16}$ Através do de Buenos Aires são protegidos os investidores de países não-pertencentes ao bloco. Para mais detalhes ver ROWAT; LUBRANO; PORRATA JUNIOR (1997. p. 98-100). Ver também DROMI SAN MARTINO (2002, p. 282-283).

17 Devido ao seu caráter de documento de direito internacional público, não estão em vigor os 28 artigos do Protocolo para todos os Estados-partes. Da mesma forma se encontra o Protocolo de harmonização de normas sobre desenho (Decisão n. 16/98). Sobre o sistema de propriedade industrial no Mercosul, bem como para acesso ao texto e comentários do Protocolo referido, ver DARTAYETE (1999, p. 68-80). Também de forma abrangente sobre propriedade industrial no Mercosul, onde as decisões citadas são referidas, ver HASSEMER, Michael. Gewerbliche Schutzrechte im MERCOSUR. Im. BASEDOW, Jürgen; SAMTLEBEN, Jürgen (Hrsg.). Wirtschaftsrecht des MERCOSUR: Horizont 2000, p. 121-141. E, resumidamente, ver FIGUERED0, 2002, p. 88-90.

18 Uma visão dos âmbitos jurídicos já adaptados e dos com perspectivas de o serem no futuro pode ser vista em SILVA, 2002, p. 87-98. Sobre a possibilidade de harmonização do direito societário interno dos países do Mercosul, em especial o das sociedades anônimas, ver FARIA, Guiomar T. Estrella. As sociedades comerciais e a formação dos blocos econômicos de nações. Im: BASSO, Maristela (Org.). Mercosul: seus efeitos jurídicos, econômicos e políticos nos estados-membros, p. 211-241.

190 tema do consumidor desenvolveu-se como uma proposta institucional (MARQUES, 2001, p. 732-739). 0 Mercosul não seria classificado como um processo de verdadeira integração e sim apenas como um processo inicial de integração, o que afeta gravemente a sua possibilidade de legislar e impor uma legislação em matéria de direitos do consumidor. 
71 | InterAção

defesa do consumidor, instituindo normas materiais ${ }^{20}$ sobre uma variedade de aspectos do tema ${ }^{21}$ (MARQUES, 2004, p. 414-419), legislação que, no entanto, não era imediatamente coercitiva no plano interno. O projeto de Protocolo foi aprovado e assinado pelo Ministério da Justiça brasileiro, em 1997, mas foi recusado pela Delegação brasileira na Comissão de Comércio do Mercosul pois poderia revogar cerca de vinte e seis artigos do Código de Defesa do Consumidor brasileiro (MARQUES, 2004, p. 420). Uma harmonização afastaria o viés da existência de legislação de proteção dos direitos do consumidor em uns países (vista como uma conquista social) e em outros não (desigualdade legislativa). A ideia era que a norma do Mercosul representasse um avanço nas legislações do Paraguai e do Uruguai e não um retrocesso nas da Argentina e do Brasil (MARQUES, 1997, p. 79-82).

Em 17 de dezembro de 1996, em Fortaleza, foi assinado o Protocolo de Defesa da Concorrência do Mercosul ${ }^{22}$, em uma tentativa de harmonização das normas de direito da concorrência. Este Protocolo, apesar de assinado pelos quatro Estados-partes, foi incorporado por apenas dois países, o Paraguai e o Brasil2 $^{23}$. Antes que fosse incorporado pelos outros Estados, o Protocolo de Fortaleza foi revogado pelo Acordo de Defesa da Concorrência do Mercosul, aprovado pelo Conselho do Mercado Comum (CMC) em dezembro de 2010 que respondia aos anseios dos Estados-partes por uma agenda mínima que

\footnotetext{
${ }^{20}$ Segundo MARQUES (2004, p. 415), as regras materiais sobre a proteção do consumidor se dividem em dois tipos: aquelas que interessam apenas indiretamente à proteção do consumidor e que somente de forma reflexa significam uma preocupação do Mercosul com os consumidores e aquelas elaboradas pelo Comitê Técnico 7, em forma de resolução, para formar um corpo unitário de normas, que se denominaria Protocolo Comum de Defesa do Consumidor e que seria uma espécie de Código de Defesa do Consumidor do Mercosul.

${ }^{21}$ Sobre a atividade legislativa do Mercosul ver DREYZIN DE KLOR, Adriana. El Mercosur: Generador de una nueva fuente de derecho internacional privado. Buenos Aires: Zavalía, 1997. 395 p.

22 Decisão do Conselho Mercado Comum n. 18/96. Segundo o Protocolo de Ouro Preto, uma decisão é obrigatória, mas não tem aplicação imediata, uma vez que deve ser internalizada por cada um dos Estados-partes.

${ }^{23}$ No Brasil, o Protocolo foi incorporado pelo Decreto n 3.602 em setembro de 2000.
} 
fosse mais condizente com a realidade intergovernamental (GUIMARÃES, 2016, p. 256).

A harmonização legislativa no Mercosul, a qual tem a tarefa de apoiar a integração, não tem sido fácil, como já apontado. Os atuais problemas em termos de harmonização ${ }^{24}$ dizem respeito à ausência de normas nacionais a harmonizar, em alguns países, bem como às características bastante diferentes das leis editadas por outros.

\section{A VENEUELA COMO MEMBRO PERMANENTE}

O grande tema da agenda do Mercosul, nos últimos anos, é a passagem da Venezuela de Estado associado para Estado-parte, assumindo a característica de membro permanente. Ainda que determinadas vantagens possam ser mencionadas ${ }^{25}$, os argumentos temerosos quanto à entrada da Venezuela no bloco foram evidenciados ao questionar, principalmente, a sua democracia ${ }^{26}$ -

\footnotetext{
${ }^{24}$ Os problemas parecem ser mundiais. A obra de Erik Jayme apresenta quatro valores da cultura pós-moderna no direito - pluralismo, comunicação, narração e retour des sentiments, sendo o Leitmotive da pós-modernidade a valorização dos direitos humanos -, a influenciar o desenvolvimento do direito e da solução dos conflitos de leis e de jurisdições, como o fio condutor da produção normativa contemporânea (JAYME, 1995, p. 33-37 e p. 246-264). 250 país tem vinte e sete milhões de consumidores/habitantes, quase um milhão de quilômetros quadrados, um Produto Interno Bruto respeitável de 1/7 do mesmo índice brasileiro. Com a Venezuela, o Produto Interno Bruto do Mercosul passaria para um trilhão de dólares, o que representaria setenta e seis por cento do mesmo índice da América do Sul. Ademais, o país tem uma história integracionista muito rica, que passa pela personalidade do libertador Simón Bolívar, nascido em Caracas, em 1783. Geograficamente, o seu ingresso permitiria a ligação do Caribe com a Patagônia. Conferir os esforços de Bolívar para a codificação do DIP na obra de FERNÁNDEZ ARROYO (1994, p. 81-87).
}

${ }^{26} 0$ ano de 2007 foi repleto de fatos pitorescos para a democracia no país. Primeiro, a Rádio Caracas Television (RCTV), a mais antiga estação privada de televisão da Venezuela e a única de oposição com alcance nacional, foi retirada do ar e substituída por um novo canal estatal no final de maio. A estação não teve a sua concessão de transmissão renovada pelo Governo do Presidente Hugo Chaves. 0 Presidente da Venezuela também entregou, neste ano, ao Congresso um projeto de reforma constitucional que implementava uma reeleição contínua. Com a proposta, o mandatário venezuelano buscava trocar a ordem política e econômica por um modelo também conhecido como socialismo petroleiro. Na época, além do Legislativo, o presidente também detinha o controle da Suprema Corte, de toda a máquina administrativa federal, das estatais de petróleo e da infraestrutura de quase todos os governos estaduais. 
73 | InterAção

tendo em vista que o Mercosul possui, desde 1992, uma cláusula democrática estabelecida em Ushuaia, na Argentina. Em 2005, a Venezuela solicitou a adesão ao Mercosul.

O Protocolo de Adesão da Venezuela foi aprovado em 2007 pela Argentina e pelo Uruguai, e em 2010 pelo Brasil. Já o Paraguai relutava em aceitar a adesão venezuelana. Em 2012, o então presidente paraguaio Fernando Lugo sofreu impeachment que resultou na suspensão do Paraguai do Mercosul - os países deliberaram "ter havido uma ruptura da ordem democrática no Paraguai e, com base nesta avaliação, decidiram suspender a participação do Paraguai nos órgãos do Mercosul até que se verificasse o pleno restabelecimento da ordem democrática naquele país" (LAFER, 2013, p. 21). No mesmo momento, em 2012, com o Paraguai suspenso, a Venezuela foi incorporada ao Mercosul pelo demais países, ficando o retorno do Paraguai condicionado à aprovação desta incorporação.

\section{A SUSPENSÃO DA VENEZUELA}

A adesão da Venezuela como membro permanente no Mercosul foi, como visto, controversa, assim como a sua participação posteriormente no bloco. Em dezembro de 2016, a Venezuela foi suspensa pela primeira vez do Mercosul em razão do descumprimento de compromissos assumidos no Protocolo de Adesão firmado em 2006. Em agosto de 2017, a Venezuela “foi notificada da suspensão de todos os seus direitos e obrigações inerentes a sua condição de Estado Parte do Mercosul, em conformidade com o disposto no segundo parágrafo do artigo $5^{\circ}$ do Protocolo de Ushuaia" 27.

${ }^{27}$ Fonte: <http://www.mercosul.gov.br> Acesso em: 29 out. 2017. 
74 | InterAção

\section{A DEFESA DO PROCESSO DE INTEGRAÇÃO}

Do ponto de vista político e econômico, instituições com poderes supranacionais semelhantes aos daqueles da União Europeia seriam inadequadas ao Mercosul, ademais de enfrentarem obstáculos de ordem constitucional $^{28}$. Há uma parte da doutrina que tem por elogiável a experiência supranacional, mas que também acredita ser adequado o Mercosul restringir-se, no presente momento e estágio da integração, ao modelo intergovernamental. Assim CACHAPUZ DE MEDEIROS (1997, p. 176), para quem é "forçoso reconhecer (...) que o sistema atual de solução de controvérsias do Mercosul é apropriado, pois condiz com o estágio de integração em que se encontram os Estados-membros. Futuramente, dependendo da marcha do processo integracionista, é lícito pensar em um tribunal supranacional para o Mercosul, que não precisará ser cópia exata do modelo europeu, pois existem importantes diferenças entre os dois espaços" ${ }^{29}$. Da mesma forma se expressa COSTA e SILVA (1997, p. 51), para quem "cabe ao Mercosul primeiramente viabilizar-se como projeto integracionista sub-regional, para depois pensarmos na criação de instituições mais complexas, mais caras e mais burocratizadas para a integração (...), evitando, no momento, órgãos de caráter supranacional”.

Uma defesa mais veemente parece vir do exterior. WEHNER (1999, p. 46) fala da funcionalidade de um novo tipo de projeto de integração (Funktionsfähigkeit eines neuartigen Integrationsprojektes), ao escrever sobre o Mercosul. Disso pode se depreender muitas coisas, como por exemplo que esse é o processo que se tem, assim foi escolhido, que pode funcionar e que com ele é

${ }^{28}$ Que em relação ao Brasil podem ser conferidos em MARTINS (2002, p. 137-185).

29 Neste estágio da integração, uma Corte ao modelo comunitário também é considerada de inutilidade prática, com fundamento na não ou na pouca utilização do próprio sistema arbitral no Mercosul e em outros processos de integração (BAPTISTA, 1998, p. 69). 
devido viver. E é um novo tipo, que tem suas particularidades, que o diferencia de todos os outros automaticamente comparáveis. A primeira apontada é a facilidade e simplicidade da estrutura ${ }^{30}$, cunhada na flexibilidade do Tratado ${ }^{31}$, o que é por sinal um dos seus princípios ${ }^{32}$, na transitoriedade, simplicidade do processo normativo, e ainda que tudo isso durante bom tempo nem funcionários exigiu. A segunda é o caráter de top-down-integration, assim o de uma integração que venha de cima para baixo, isto é, dos governos ou de seus representantes. A terceira envolve diferenciações com o modelo unional, como a impossibilidade de comparação de seus órgãos, a então ausência de um tribunal permanente e a opção pela intergovernabilidade. Por fim, vê o autor diferenciações (Unterschiedlichkeit der Mercosur-Methode) ao compará-lo com outras tentativas sul-americanas.

O mérito do levantamento feito está na avaliação deste novo método, tido como sui generis ${ }^{33}$. Inicia ele por perguntar, ao promover uma nova avaliação do método de integração (Neubewertung der Integrationsmethode), se as desconfianças com o processo também em casos concretos teriam fundamento. Lembra que o ponto de partida dos processos Mercosul e União Europeia e a realidade econômica dos países são diferentes, que era sabido que o processo não atingiria um mercado comum em apenas quatro anos, que o termo no contexto em que foi citado representava mais um desejo político que um termo técnico, e que os regimes presidencialistas dos países têm seus reflexos na condução da integração, motivos pelos quais, ademais dos culturais, sociais e

30 Também para TEPEDINO (1999, p. 265) a formulação institucional do Mercosul "é muito pragmaticamente simples".

31 Assim também para VENTURA (2003, p. 52), para quem "a flexibilidade foi muitas vezes apresentada como a chave do sucesso do Mercosul. Com efeito, o fato de não ter atingido bruscamente um mercado comum pode ter permitido sua sobrevivência em meio a sucessivas crises econômicas vividas pelos Estados que o compõem".

32 Sobre os princípios de flexibilidade, gradualidade, equilíbrio e reciprocidade no Mercosul ver FARIA, 1993, p. 224.

${ }^{33}$ Assim também visto em VENTURA, 2003, p. xli e 317. 
econômicos, nem sempre uma comparação com a União Europeia pode ser feita. Além disso, que modelos tentados mais parecidos com o da União Europeia, como o Pacto Andino, também não são plenos de sucesso ${ }^{34}$ : eles poderiam conduzir à criação de instituições e burocratização (Mercocracia, em alusão à Eurokratie) ao invés de avanços na integração. Antes pelo contrário, a estrutura intergovernamental utilizada na relação bilateral entre Brasil e Argentina anterior ao Mercosul apresentou sucesso comercial expressivo, tendo inclusive conduzido em termos finais à assinatura do Tratado de Assunção, ainda que um processo sem estruturas sólidas seja sensível e suscetível. Para fugir daquilo, vê aqui flexibilidade e orientação para as necessidades (Flexibilität und Bedarfsorientiertheit) ${ }^{35}$. E mesmo que o processo, no momento de sua análise, não apresentaria uma maturidade para um sistema de solução de controvérsias permanente.

Logo após observa que o processo tem as opções abertas, ao invés de rigidez. E mesmo um caráter de irreversibilidade (Unumkehrbarkeit; point of no return ${ }^{36}$ ). Parece sempre que se não existisse a União Europeia, isto é, se não existisse um modelo de comparação, o método escolhido aqui não seria tão criticado pela doutrina ${ }^{37}$. Esse suposto caráter de irreversibilidade, que lhe

\footnotetext{
34 Sobre este processo de integração ver JAEGER JUNIOR, 2006, p. 34-37. WEHNER (1999, p. 46 e p. 58-59) observa que os processos anteriores sem estrutura supranacional, como a Alalc e a Aladi não obtiveram sucesso, mas que processos com estrutura complexa, em parte amplamente comparável com a estrutura comunitária, como 0 Pacto Andino, também não, o que deixa parecer que a solução possivelmente não reside aí. De fato, segundo VENTURA (2003, p. 85), "o fracasso da integração andina dever-se-ia, portanto, à rigidez do modelo adotado e 0 sucesso do Mercosul só poderia ser obtido graças à flexibilidade e à maleabilidade institucionais", elementos que são justamente considerados "como um trunfo, não como desvantagem" do processo (2003, p. 55-56).

${ }^{35}$ Assim também parece ser deduzido da leitura de VENTURA (2003, p. 101, 599 e 608).

${ }^{36}$ Expressão, em outro contexto, também usada por ALMEIDA (2000, p. 27).

${ }^{37}$ ALMEIDA (2003, p. 111-122) refere-se a um "fantasma da UE".
} 
empresta funcionalidade, retira dele a alternativa de não crescer, de não se desenvolver ${ }^{38}$. Enfim, o método escolhido colheria consentimentos.

O debate existente entre qual seria o melhor modelo, intergovernamental ou supranacional, ficou prejudicado nos últimos anos em função de problemas econômicos e políticos que afetaram os Estados-partes do Mercosul. Tanto crises econômicas como questões políticas, a exemplo da turbulência enfrentada com a Venezuela, adiam tentativas de harmonização legislativa e afastam um avanço integracionista no bloco.

\section{CONSIDERAÇÕES FINAIS}

A fase áurea do Mercosul deu-se no período que antecedeu à crise econômica dos seus Estados-partes. Essa teve imediata repercussão no bloco. As providências para recuperar a credibilidade do Mercosul, além do impulso político e da diminuição das divergências econômicas dos governos envolvidos, passam pela essencialidade de conferir ao processo de cooperação maior grau de segurança jurídica.

Apesar do atual consenso da doutrina quanto à existência de um ordenamento jurídico do bloco, passados mais de vinte anos da entrada em vigor do Protocolo de Ouro Preto, o Mercosul não atingiu o objetivo de compor uma ordem jurídica com regras uniformes e obrigatórias. Tal situação pode ser atribuída ao sistema de solução de controvérsias (não obstante o avanço empreendido desde a implementação do Tribunal Permanente de Revisão, via

38 WEHNER (1999, p. $130-144$ e p. $169-171)$, fundamenta a irreversibilidade no sucesso parcial atingido em determinados objetivos, no seguimento do plano de liberação comercial e na existência de metas então futuras, como o Programa de Ação do Mercosul para 0 ano de 2000 - Decisão n. 9/95. Uma outra posição parece ter VENTURA (2003, p. 549 e p. xxxv), para quem "a irreversibilidade do Mercosul é mais do que nunca um mito" e "ele não passa de uma ideia em vias de materialização". 
Protocolo de Olivos), que não permite a criação sólida de jurisprudência, o que prejudica a interpretação normativa uniforme. Igualmente, é problemático o sistema de incorporação dos regulamentos originados do Mercosul, ao qual foram conferidos os mecanismos próprios do direito internacional público clássico, sendo que esses não garantem a segurança na efetiva vigência desse direito de cooperação. Tais fatos contribuem para a instabilidade e a imprevisibilidade jurídicas reinantes.

Diante dessas observações, pode-se concluir pela inexistência de um direito comunitário, ou direito da integração no Mercosul, cuja natureza é de direito internacional público ${ }^{39}$. Por outro lado, destaca-se que os Estados-partes não intentaram construir uma "bela catedral gótica comunitária" pela simples estética de um ideal integracionista, sendo seus objetivos o crescimento econômico e social das populações da região, a promoção dos interesses nacionais no plano internacional e a elevação do bem-estar social no Cone $\mathrm{Sul}^{40}$.

Uma das características mais marcantes do processo é a flexibilidade em torno de sua estrutura, cujos elementos vêm sendo construídos de forma paulatina. Exemplo disso é a instituição do Parlamento do Mercosul41. Ao mesmo tempo, porém, o não-aprofundamento das relações institucionais, marcadamente pela renúncia à supranacionalidade, em prol da

\footnotetext{
39 KLEINHEISTERKAMP (2002, p. 333-335), em opinião diversa, afirma ser possível conceber, no mecanismo de incorporação normativa do Mercosul um direito derivado, semelhante ao direito secundário do ordenamento jurídico da União Européia. 0 ponto decisivo para tal percepção é que, tanto nas fontes primárias, parcialmente, quanto nas fontes secundárias, em maior extensão, mesmo na forma de direito internacional público, concedem-se direitos e impõem-se obrigações diretamente aos cidadãos dos Estados Partes, com a finalidade de integração econômica e unificação das legislações. Cria-se, desse modo, um direito da integração, que, por um lado, tem qualidade de direito interno aplicável aos cidadãos e, por outro lado, advém das obrigações internacionais dos Estados-partes. De acordo com 0 autor alemão, este caráter duplo de normas internacionais uniformizadas, em conjunto com o superior objetivo da integração regional, autoriza afirmar a existência de um direito comunitário do Mercosul, mesmo sem a característica da supranacionalidade.
}

40 A expressão é do diplomata Paulo Roberto de Almeida. ALMEIDA, Paulo Roberto de. Le Mercosud: un Marche commun pour l'Amérique du Sud. Paris: L'Hartmann, 2000. Apud CANÇADO TRINDADE, Otávio A. D. O Mercosul no direito brasileiro: incorporação de normas e segurança jurídica, p. 46-47.

${ }^{41}$ Aprovado no Brasil pelo Decreto $\mathrm{n}^{\circ}$ 6.105, de 30 de abril de 2007. 
79 | InterAção

intergovernamentalidade, funciona como um dos principais obstáculos à integração econômica sul-americana. Sugestões para a superação da crise do Mercosul passam, portanto, pela implementação de certo grau de supranacionalidade em instituições-chave, como no sistema de solução de conflitos e na incorporação normativa.

O Brasil é o país que mais incorporou normas provenientes do Mercosul (74,62\%). Os mecanismos de incorporação apresentam, porém, inconvenientes, devido a sua notável dispersão. A internalização é feita por meio de decretos ou atos dos Poderes Legislativo (decreto legislativo) e Executivo (decreto presidencial) e de internalização via decretos ou atos administrativos apenas do Executivo (Administração Direta ou Indireta) (CANÇADO TRINDADE, 2007, p. 26-27). Essa descentralização da incorporação, por ser difusa, é lenta, e não traz a devida publicidade e controle que o processo merece. Há, felizmente, iniciativas individuais positivas de órgãos do governo, como o Ministério da Saúde, que publica projetos de normas do Mercosul, o que permite maior transparência no processo legislativo e pode evitar futuros questionamentos quanto à legalidade e à constitucionalidade dessas normas (CANÇADO TRINDADE, 2007, p. 154). Sobretudo, a centralização do processo de incorporação reforçaria a previsibilidade e a estabilidade das normas no direito brasileiro.

Um dos sucessos da legislação proveniente do Mercosul está na cooperação judicial internacional. O Protocolo de Las Leñas e o Protocolo de Medidas Cautelares formam uma codificação de cooperação judicial na região do Cone Sul e, em distintos aspectos, avançam em relação às convenções antecedentes (TELLECHEA BERGMAN, 2002, p. 25), sendo aplicados regularmente (ARAUJO, 2006, p. 283). 
80 InterAção

Apesar das críticas quanto à estrutura institucional, o Mercosul consiste na iniciativa diplomática de cooperação mais profunda ocorrida na América Latina nas últimas décadas, ao gerar a expansão das relações de cooperação e de comércio entre os Estados-partes. A despeito das polêmicas sobre seu futuro, o Mercosul é um valioso mecanismo para o intercâmbio comercial entre países com iniciativa de integração, notadamente a União Europeia.

A discussão sobre qual seria o melhor modelo, intergovernamental ou supranacional, segue enfrentando reflexos dos problemas econômicos e políticos dos Estados-partes do Mercosul. A busca por uma harmonização legislativa segue prejudicada ora por fragilidades econômicas, ora por controvérsias políticas.

\section{REFERÊNCIAS}

ALMEIDA, Paulo Roberto de. O Brasil e o futuro do MERCOSUL: dilemas e opções. In: CASELLA, Paulo Borba (Coord.). MERCOSUL: integração regional e globalização. Rio de Janeiro: Renovar, 2000. p. 13-38.

. O Mercosul em crise: que fazer? Tempo Exterior: revista de análise de estudios internacionales. Baiona: Instituto Galego de Análise e Documentación, v. IV, n. 6, jan./jun. 2003. p. 111-122.

ARAUJO, Nadia de. Contratos internacionais: autonomia da vontade, Mercosul e convenções internacionais. 3. ed. Rio de Janeiro: Renovar, 2004. 368 p.

ARAUJO, Nádia de. Direito internacional privado: teoria e prática brasileira. 3. ed. Rio de Janeiro: Renovar, 2006. 514 p.

BARRAL, Welber. O Protocolo de Olivos e as controvérsias no Mercosul. In: HOFMEISTER, Wilhelm; TREIN, Franklin. Anuário Brasil-Europa 2002: solução de controvérsias, arbitragem comercial e propriedade intelectual. Rio de Janeiro: Konrad Adenauer, 2003. p. 83-96. 
81 InterAção

BAPTISTA, l.uiz Olavo. Impacto do Mercosul sobre o sistema legislativo brasileiro. In: BAPTISTA, Luiz Olavo; MERCADANTE, Araminta de Azevedo; CASELLA, Paulo Borba (orgs.). Mercosul: das negociações à implantação. 2. ed. São Paulo: LTr, 1998. p. 17-30.

BIANCHI, Patrizio. Construir el mercado: Lecciones de la Unión Europea - el desarrollo de las instituciones y de las políticas de competitividad. Buenos Aires: Universidad Nacional de Quilmes, 1997. 260 p.

CACHAPUZ DE MEDEIROS, Antonio Paulo. Tribunais supranacionais e aplicação do direito comunitário: aspectos positivos e negativos. In: VENTURA, Deisy de Freitas Lima (Org.). Direito Comunitário do MERCOSUL. Porto Alegre: Livraria do Advogado, 1997. p. 162-176.

CANÇADO TRINDADE, Otávio A. D. O Mercosul no Direito Brasileiro: incorporação de normas e segurança jurídica. Belo Horizonte: Del Rey, 2007. 178 p.

COSTA e SILVA, Eugênio da. A concorrência no Mercosul: considerações preliminares. Revista de Direito Econômico. Brasília: Conselho Administrativo de Defesa Econômica, n. 25, jan./jul. 1997. p. 45-51.

DARTAYETE, María Cristina. Armonización de normas en el Mercosur. Revista de Derecho del Mercosur. Buenos Aires: La Ley, a. 3, n. 1, fev. 1999. p. 63-80.

DREYZIN DE KLOR, Adriana. El Mercosur: Generador de una nueva fuente de derecho internacional privado. Buenos Aires: Zavalía, 1997. 395 p.

DROMI SAN MARTINO, Laura. Derecho Constitucional de la Integración. Buenos Aires: Ciudad Argentina, 2002. 692 p.

FARIA, Guiomar T. Estrella. As sociedades comerciais e a formação dos blocos econômicos de nações. In: BASSO, Maristela (Org.). Mercosul: seus efeitos jurídicos, econômicos e políticos nos estados-membros. 2. ed. Porto Alegre: Livraria do Advogado, 1997. p. 211-241.

FARIA, José Ângelo Estrella. O Mercosul: princípios, finalidades e alcance do Tratado de Assunção. Brasília: Subsecretaria Geral de Assuntos da Integração, Econômicos e do Comércio Exterior. Núcleo de Assessoramento Técnico, 1993. $193 \mathrm{p}$.

FERNÁNDEZ ARROYO, Diego P. La codificación del Derecho internacional privado en América Latina. Madrid: Beramar, 1994. 448 p.

FIGUEREDO, Julio. Derecho de la competencia e integración económica: la situación en el Mercosur. In: CUADERNOS de EPOCA: Integración económica 2. Buenos Aires: Ciudad Argentina, 2002. p. 33-101. 
82 | InterAção

GRATIUS, Susanne. Der Mercosur im Brennpunkt der Integration. Jahrbuch Internationale Politik 1995-1996. München: R. Oldenbourg, v. 22, 1988. p. 304-315.

GUIMARÃES, Marcelo Cesar. Os Novos Rumos do Direito Antitruste no MERCOSUL: o Acordo de Defesa da Concorrência e a Consolidação da Cooperação Internacional na Região. Revista de Defesa da Concorrência. v. 4. n. 1. 2016. p. 237-278.

HACIA la III Cumbre Unión Europea - América Latina y el Caribe: Balances y perspectivas. Madrid: Red de Cooperación Euro-latinoamericana (RECAL), doc. 10/2004, jan. 2004. 52 p.

HASSEMER, Michael. Gewerbliche Schutzrechte im MERCOSUR. In: BASEDOW, Jürgen; SAMTLEBEN, Jürgen (Hrsg.). Wirtschaftsrecht des MERCOSUR: Horizont 2000. Baden-Baden: Nomos Verlagsgesellschaft, 2001. p. 121-141.

JAEGER JUNIOR, Augusto. Liberdade de concorrência na União Européia e no Mercosul. São Paulo: LTr, 2006, 807 p. Temas de direito da integração e comunitário. São Paulo: LTr, 2002. $262 \mathrm{p}$.

JAYME, Erik. Identité culturelle et intégration: le droit internacional privé postmoderne. Recueil des Cours. The Hague: The Hague Academy of International Law, 1995. t. 251. p. 9-268.

KLEINHEISTERKAMP, Jan. A interpretação uniforme do direito comunitário - um ensaio prático sobre a metodologia do direito do MERCOSUL. In: RODAS, João Grandino (coord.). Contratos Internacionais. 3. ed. São Paulo: Revista dos Tribunais, 2002.

LAFER, Celso. Descaminhos do Mercosul - a suspensão da participação do Paraguai e a incorporação da Venezuela: uma avaliação crítica da posição brasileira. Revista Política Externa: Mercosul = - Paraguai + Venezuela. v. 21. n. 3. 2013. p. 19-27.

MARQUES, Cláudia Lima. A proteção do consumidor: aspectos de direito privado regional e geral. In: XXVII Curso de Derecho Internacional. Rio de Janeiro, Washington: Comité Jurídico Interamericano, Organización de los Estados Americanos, 2001. p. 657-779.

. Confiança no comércio eletrônico e a proteção do consumidor: um estudo dos negócios jurídicos de consumo no comércio eletrônico. São Paulo: Revista dos Tribunais, 2004. 
. Liberdade de estabelecimento e de prestação de serviços no

Mercosul: Instrumentos Legislativos sobre Formação de Recursos Humanos. In: MOROSINI, Marilia (Coord.). Mercosul/Mercosur: Políticas e Ações Universitárias. Porto Alegre: UFRGS, 1998. p. 25-46.

. O "Direito do Mercosul": Direito oriundo do Mercosul, entre Direito Internacional Clássico e Novos Caminhos de Integração. Revista da Faculdade de Direito da Universidade Federal do Paraná. Porto Alegre: Síntese, v. 35, 2001. p. 73-100.

. Regulamento comum de defesa do consumidor do Mercosul: primeiras observações sobre o Mercosul como legislador da proteção do consumidor. Revista de Direito do Consumidor. São Paulo: Revista dos Tribunais, n. 23-24, jul./dez. 1997. p. 79-103.

MARTINS, Eliane Maria Octaviano. Competitividade empresarial e Mercosul. Boletín Latinoamericano de Competencia. Bruxelas, nov. 2001, n. 13, p. 50-70.

MARTINS, Renata Rocha de Mello. Verfassungskonformität des MERCOSUR in Brasilien. Baden-Baden: Nomos Verlagsgesellschaft, 2002. 221 p.

PISCITELLO, Daniel Pavón; SCHMIDT, Jan Peter. Der EuGH als Vorbild: Erste Entscheidung des ständigen Mercosur-Gerichts. Europäische Zeitschrift für Wirtschaftsrecht. Frankfurt am Main: Verlag C. H. Beck, Heft 10, 2006. p. 301-304.

RAMOS, Dante Marcelo. Das Wettbewerbsschutz-Protokoll des Mercosur: eine Darstellung anhand der Wettbewerbsordnungen Argentiniens und Brasiliens und im Vergleich mit der Europäischen Gemeinschaft. Frankfurt am Main: Peter Lang, 2000. $199 \mathrm{p}$.

ROWAT, Malcolm; LUBRANO, Michele; PORRATA JUNIOR, Rafael. Competition Policy and MERCOSUR. Washington: World Bank, 1997.110 p.

SALOMÃO FILHO, Calixto; SAMTLEBEN, Jürgen. Der Südamerikanische Gemeinsame Markt: eine rechtilche Analyse des Mercosur (Teil I). Zeitschrift für Wirtschafts- und Bankrecht. Frankfurt am Main: Herausgebergemeinschaft Wertpapier-Mitteilungs, 46. Jahrgang, Heft 33, ago. 1992. p. 1345-1352.

. Der Südamerikanische Gemeinsame Markt: eine rechtilche Analyse des Mercosur (Teil II). Zeitschrift für Wirtschafts- und Bankrecht. Frankfurt am Main: Herausgebergemeinschaft Wertpapier-Mitteilungs, 46. Jahrgang, Heft 34, ago. 1992. p. 1385-1392.

SAMTLEBEN, Jürgen. “Das Recht des Mercosur”: wichtig für Europa?

Europäische Zeitschrift für Wirtschaftsrecht. Frankfurt am Main: Verlag C. H. Beck, 9. Jahrgang, Heft 3, fev. 1998. p. 65. 
. Der Südamerikanische Gemeinsame Markt (MERCOSUR) und seine neue Verfassung. Zeitschrift für Wirtschafts- und Bankrecht. Frankfurt am Main: Herausgebergemeinschaft Wertpapier-Mitteilungs, 50. Jahrgang, Heft 44, nov. 1996. p. 1997-2205.

Ein Gerichtsstandsübereinkommen für den Südamerikanischen Gemeinsamen Markt (MERCOSUR). Praxis des Internationalen Privat- und Verfahrensrechts. Bielefeld: Gieseking, 15. Jahrgang, n. 2, mar./abr. 1995, p. 129132.

Der MERCOSUR als Rechtssystem. In: BASEDOW, Jürgen;

SAMTLEBEN, Jürgen (Hrsg.). Wirtschaftsrecht des MERCOSUR: Horizont 2000. Baden-Baden: Nomos Verlagsgesellschaft, 2001. p. 51-94.

SCHMIDT, Jan Peter. Neue Impulse durch institutionelle Reformen - der Mercosur ist wieder auf Kurs. Europäische Zeitschrift für Wirtschaftsrecht. Frankfurt am Main: Verlag C. H. Beck, Heft 5, 2005. p. 139-142.

SEGUNDO informe sobre la aplicación del derecho del MERCOSUR por los tribunales nacionales (2004). Montevideo: Secretaría del Mercosur, 2007. 587 p.

SILVA, Elaine Ramos da. Rechtsangleichung im Mercosul: Perspektiven für das Niederlassungsrecht von Gesellschaften anhand von Erfahrungen in der Europäischen Union. Baden-Baden: Nomos Verlagsgesellschaft, 2002. 200 p.

TELLECHEA BERGMAN, Eduardo. La dimensión judicial del caso privado internacional en el ámbito regional: Análisis en especial de los Protocolos acordados en el Mercosur sobre Cooperación, Asistencia Jurídica Internacional, Cumplimento de Medidas Cautelares, Reconocimiento de Sentencias Extranjeras y Jurisdición Internacional. Montevideo: Fundación de Cultura Universitária, 2002. 150 p.

TEPEDINO, Gustavo. Tecniche legislative ed interpretative nell'armonizzazione del diritto privato comunitario: l'esperienza del Mercosul. In: MELLO, Celso de Albuquerque (Coord.). Anuário direito e globalização: a soberania. Rio de Janeiro: Renovar: 1999. p. 263-276.

VENTURA, Deisy. As assimetrias entre o Mercosul e a União Européia: os desafios de uma associação inter-regional. Barueri: Manole, 2003. 694 p.

XAVIER BASALDÚA, Ricardo. Mercosur y derecho de la integración. Buenos Aires: Abeledo-Perrot, 1999. 910 p.

WEHNER, Ulrich. Der Mercosur: Rechtsfragen und Funktionsfähigkeit eines neuartigen Integrationsprojektes und die Erfolgsaussichten der interregionalen Kooperation mit der Europäischen Union. Baden-Baden: Nomos Verlagsgesellschaft, 1999. $253 \mathrm{p}$. 